\title{
Sonic hedgehog and pancreatic-duodenal homeobox 1 expression distinguish between duodenal and pancreatic gastrinomas
}

\author{
Volker Fendrich ${ }^{1}$, Ricarda Ramerth ${ }^{1}$, Jens Waldmann ${ }^{1}$, Katja Maschuw ${ }^{1}$, \\ Peter Langer ${ }^{1}$, Detlef K Bartsch ${ }^{1}$, Emily P Slater ${ }^{1}$, Annette Ramaswamy ${ }^{2}$ \\ and Matthias Rothmund ${ }^{1}$
}

Departments of ${ }^{1}$ Surgery and ${ }^{2}$ Pathology, Philipps-University Marburg, Baldingerstraße, D-35043 Marburg, Germany

(Correspondence should be addressed to V Fendrich; Email: fendrich@med.uni-marburg.de)

\begin{abstract}
Some $80-90 \%$ of gastrinomas are located in the gastrinoma triangle, which includes the duodenum, the pancreatic head, and the hepatoduodenal ligament. The natural history of the tumors depends on their origin. Duodenal gastrinomas are much less aggressive than pancreatic primaries and infrequently develop liver metastases. The reason therefore is unclear. The transcription factor pancreatic-duodenal homeobox $1(\mathrm{Pdx} 1)$ is important in differentiation and development of the pancreas and duodenum. In embryonic development, Sonic hedgehog (Shh) expression establishes a sharp molecular boundary, which allows for the proper patterning of the duodenal and pancreatic epithelium. Pancreatic polypeptide (PP) is expressed in pancreatic islets and is known to be expressed in pancreatic endocrine tumors. This study aims to clarify the expression pattern of Pdx1, Shh, and PP in duodenal and pancreatic gastrinomas. Tissue from 15 patients with duodenal and from 11 patients with pancreatic gastrinomas that underwent surgery between 1987 and 2007 at our institution because of a gastrinoma were evaluated by immunohistochemistry (IHC). Furthermore, tissue from lymph node metastases from two patients with a so far undetected primary gastrinoma was analyzed. IHC revealed strong Pdx1 expression in pancreatic gastrinomas, but not in duodenal gastrinomas. By contrast, there was no Shh expression detectable in pancreatic gastrinomas, but found in all duodenal gastrinomas. This pattern was also true for associated metastases. Shh expression combined with absence of Pdx1 expression in lymph node metastases from patients with an unknown location of the primary suggests a so far undetected duodenal gastrinoma. We show for the first time that only pancreatic, but not duodenal gastrinomas express Pdx1. Moreover, only duodenal gastrinomas express Shh, suggesting a different genetic background of these two tumors. Whereas the expression of Pdx1 in pancreatic gastrinomas might suggest their endocrine origin from islets, duodenal gastrinomas develop from a Pdx1 negative cell cluster. The expression pattern of Pdx1, Shh, and PP in resected metastases can help to locate an otherwise undetected primary gastrinoma.
\end{abstract}

Endocrine-Related Cancer (2009) 16 613-622

\section{Introduction}

Gastrinomas, which are responsible for ZollingerEllison syndrome (ZES; Zollinger \& Ellison 1955), were originally described as pancreatic neuroendocrine tumors, but since two decades it is known that they are most commonly located within the wall of the duodenum. Eighty to ninety percent are located in the so-called gastrinoma triangle, which includes the duodenum, the pancreatic head and the hepatoduodenal ligament (Stabile et al. 1987). Eighty percent are 
situated in the first and second part of the duodenum (Hoffmann et al. 2005) correlating with the fact that this portion of the duodenum contains the majority of $\mathrm{G}$ cells, which are thought to be the cell of origin for most duodenal gastrinomas (Zogakis et al. 2003).

The origin of pancreatic gastrinomas has been an enigma. Attempts to detect gastrin in the normal pancreas had so far either failed or resulted in the misidentification of somatostatin cells as gastrin cells (Brand \& Fuller 1988). Bardram et al. (1990) showed for the first time that human pancreatic tissue contained progastrin. Thus, gastrinomas illustrate a phenotypic characteristic of neoplasia; namely, the expression of genes which are only transiently active during fetal development. Patients with sporadic ZES are found to have a solitary duodenal or pancreatic gastrinoma. In the remaining patients, ZES is part of multiple endocrine neoplasia type 1 (MEN1) syndrome (Pipeleers-Marichal et al. 1990, Thompson 1998). Size varies with the site of the tumor; pancreatic gastrinomas are often larger than $1 \mathrm{~cm}$, whereas gastrinomas of the duodenum are usually smaller (Donow et al. 1991, Sugg et al. 1993). Imaging studies fail to localize the tumor in $80 \%$ of duodenal microgastrinomas (Zogakis et al. 2003). By contrast, such studies identify $50-72 \%$ of pancreatic gastrinomas (Fendrich et al. 2007). Whereas pancreatic gastrinomas can be readily identified at exploration, duodenotomy is essential to identify duodenal gastrinomas (Sugg et al. 1993, Norton \& Jensen 2004). However, the primary duodenal lesion is sometimes not identified and only nodal metastases are found. In fact, even after reoperation ZES still persists (Fendrich et al. 2006). In this case, knowledge of the potential anatomic location of the primary tumor would allow the surgeon to focus on the pancreas or the duodenum. An elegant solution to this problem would be if resected lymph node metastases expressed a marker that could distinguish between duodenal and pancreatic gastrinoma. So far, such a marker is unknown.

Duodenal tumors are not only smaller, but also are less likely to metastasize to the liver and have a better prognosis than pancreatic gastrinomas (Donow et al. 1991, Imamura et al. 1992, Yu et al. 1999, Klöppel et al. 2007). Furthermore, patients with a ZES-related death were more likely to have a gastrinoma in the pancreas and less likely to have a duodenal gastrinoma (Yu et al. 1999). The reason for this is unclear.

The gene, pancreatic-duodenal homeobox $1(P d x l)$, belongs to the ParaHox gene family of transcription factors. In mouse embryos, at E9.5, Pdx1 expression marks the dorsal and ventral pancreatic buds and the duodenal endoderm between them (Guz et al. 1995). In the adult, Pdx1 expression is maintained in the duodenal epithelium (Miller et al. 1994, Guz et al. $1995)$ and in the insulin-secreting islet $\beta$-cells (Offield et al. 1996). It is also found in stomach and the common bile duct, suggesting that it fulfills different roles depending on the presence of other differentiation factors (Guz et al. 1995, Offield et al. 1996, Stoffers et al. 1999). Pdx1 expression in non-islet adult pancreatic tissue has been observed in many pathologic conditions that involve reactivation of embryonic signaling pathways, such as cancer and exocrine pancreatic injury and regeneration (Song et al. 1999, Jensen et al. 2005, Liu et al. 2007, Fendrich et al. 2008).

In mouse mid-gestational embryos, Sonic hedgehog (Shh) is expressed in nearly all epithelial cells lining the alimentary canal and its function is critical for proper foregut and gastrointestinal development. By contrast, Shh is excluded from the developing pancreas, but remains expressed in the surrounding stomach and duodenal epithelium (Hebrok et al. 2000, Cano et al. 2007). Thus, Shh expression establishes a sharp molecular boundary, which allows for the proper patterning of the duodenal and pancreatic epithelium. Furthermore, overexpression of Shh within the developing pancreas of transgenic Pdx1-Shh mice leads to attenuation of pancreatic phenotype and induction of an intestinal differentiation program (Apelqvist et al. 1997). The pancreatic mesoderm of Pdx1-Shh mice is transformed into an intestinal mesenchyme, replete with a bi-layered mantle of smooth muscle as is seen in the duodenum.

The majority of pancreatic endocrine tumors express and/or secret pancreatic polypeptide (PP; Strodel et al. 1984). PP was discovered in 1968, when Kimmel et al. (1968), while purifying chicken insulin, found a new peptide hormone that they named 'pancreatic polypeptide'. In mammals, virtually all of the PP-producing cells are located in the pancreas mainly within the islets, located in the periphery, and wedged between the $\mathrm{A}$ and $\mathrm{B}$ cells.

In the present study, we analyzed the expression pattern of Pdx1, Shh, and PP in duodenal and pancreatic gastrinomas. For the first time, we show that only pancreatic gastrinomas and their metastases are expressing $\mathrm{Pdx} 1$, but not Shh reflecting their pancreatic origin. By contrast, duodenal gastrinomas lack the expression of $\mathrm{Pdx} 1$ but expressing Shh, suggesting that duodenal and pancreatic gastrinomas are different tumor entities having nothing but the same hormone expression in common. 


\section{Materials and methods}

\section{Patients}

Thirty-five patients underwent surgery for duodenal or pancreatic gastrinoma and/or metastases between 1987 and April 2008 at the Department of Surgery of the Philipps-University Marburg. Seven patients had to be excluded from the study due to unavailable tissue for immunohistochemical analysis. Hence, tumor tissue from 15 patients with duodenal gastrinomas and from 11 patients with pancreatic gastrinomas was analyzed. Nineteen patients had sporadic gastrinoma, whereas nine patients had a MEN1-associated gastrinoma. MENI gene mutation analysis was performed by Taq cycle sequencing using an automated sequencer (ABI 310 Genetic Analyzer, Perkin Elmer, Waltham, MA, USA) as described previously by our group (Bartsch et al. 2005).

Furthermore, tissue from lymph node metastases from two patients with so far undetected primary gastrinomas was analyzed. The clinical records of all patients with at least one operation during this time range were analyzed with special regard to patient demographics, clinical characteristics, pathological findings, and long-term follow-up. Since 1997, the majority of patients were followed annually by biochemical testing, abdominal computed tomography, endoscopic ultrasonography, and somatostatinreceptor-scintigraphy at our hospital and the follow-up resulted from the most recent examination.

\section{Diagnosis of ZES}

The diagnosis of ZES was made in the absence of antisecretory medication: measurement of fasting serum gastrin level, the change in serum gastrin level after secretin stimulation, and the levels of basal acid output. An abnormal fasting serum gastrin level was defined as a serum gastrin concentration $>125 \mathrm{pg} / \mathrm{ml}$. A basal acid output $\geq 15 \mathrm{mEq} / \mathrm{h}$ was abnormal if the patient had no previous acid reducing surgery or $>5 \mathrm{mEq} / \mathrm{h}$ if the patient had previous acid reducing surgery. An abnormal secretin stimulation test was defined as an incremental increase in serum gastrin level $>200 \mathrm{pg} / \mathrm{ml}$ after the i.v. administration of $2 \mathrm{U} / \mathrm{kg}$ of secretin. Malignancy was determined on the basis of strict criteria of infiltrative growth, lymph node or distant metastases. Preoperative imaging routinely comprised thin-sectioned abdominal computed tomography, somatostatin-receptor-scintigraphy, and endoscopic ultrasonography.

\section{Operative procedures}

Patients underwent operative exploration to localize and resect a primary gastrinoma and lymph node or other metastases. The abdominal cavity was systematically explored for the evidence of disease. A Kocher maneuver was performed to fully mobilize the head of the pancreas and duodenum and the lesser sac was opened to examine the pancreatic body and tail. The duodenum and pancreas were carefully palpated. Patients with no evidence for pancreatic gastrinomas underwent longitudinal duodenotomy. If a primary tumor was not on the medial duodenal wall, it was elliptically excised with a margin of $2-3 \mathrm{~mm}$. Pancreatic gastrinomas were either treated by distal pancreatic resection or pylorus-preserving pancreaticoduodenectomy (PPPD) with regional lymph node dissection. For MEN1-ZES either a distal pancreatic resection to the level of the portal vein with enucleation of any tumors in the pancreatic head, a duodenotomy with excision of any tumors in the first to fourth portion of the duodenum and a peripancreatic lymph node dissection as suggested by Thompson (1998) was routinely performed until 1997. Since then, we prefer a PPPD with lymphadenectomy when the source of gastrin secretion could be regionalized to the pancreatic head region by preoperative selective arterial secretin injection angiography (Imamura et al. 1987).

\section{Pathology}

Pathologic diagnosis of a primary duodenal or pancreatic gastrinoma was made for all patients by immunohistochemical analysis for the presence of gastrin. The size of the tumor was measured and the largest diameter was documented. Lymph nodes were evaluated in a similar manner. Pathology reports were reviewed in a retrospective fashion for the size of the primary gastrinoma and the presence of positive lymph nodes.

\section{Immunohistochemical analysis of gastrinomas}

For immunolabeling, formalin-fixed and paraffin embedded archived tumor samples and corresponding normal tissues were stained as previously described (Esni et al. 2004). Briefly, slides from archived gastrinomas were heated to $60{ }^{\circ} \mathrm{C}$ for $1 \mathrm{~h}$, deparaffinized using xylene, and hydrated by a graded series of ethanol washes. Antigen retrieval was accomplished by microwave heating in $10 \mathrm{mM}$ sodium citrate buffer of pH 6.0 for $10 \mathrm{~min}$. For immunohistochemistry (IHC), endogenous peroxidase activity was quenched by 10 min incubation in $3 \% \mathrm{H}_{2} \mathrm{O}_{2}$. Non-specific binding 
was blocked with $10 \%$ serum. Sections were then probed with anti-rabbit Pdx1 (Chemicon, Temecula, CA, USA) in a dilution with $1: 100$ overnight at $4{ }^{\circ} \mathrm{C}$. For IHC, bound antibodies were detected using the avidin-biotin-complex (ABC) peroxidase method (ABC Elite Kit, Vector Labs, Burlingame, CA, USA). Final staining was developed with the Sigma FAST DAB peroxidase substrate kit (Sigma). Pancreatic islets from normal pancreatic tissue samples from our tissue bank were used as positive controls along with each batch of Pdx1 IHC staining.

\section{Statistical analysis}

Log-rank test was applied to identify significant differences. $P$ values $<0.05$ were considered statistically significant. Data were analyzed using SPSS software (Version 11; SPSS, Inc., Chicago, IL, USA).

\section{Results}

\section{Patients and clinical characteristics}

The clinical characteristics for the identified patients are given in Table 1 . A total of 28 patients with resected gastrinomas were included in the study. For the evaluation of $\mathrm{Pdx} 1$ expression, 12 males and 16 females with a median age of 49 years (range 28-73 years) at the time of surgery were included in this study. Eighteen patients had sporadic gastrinomas, whereas 10 patients had MEN1-gastrinomas. The patients with sporadic disease were older than patients with MEN1 syndrome (52 vs 45 years, $P \leq 0.05$ ) at time of surgery. Duodenal gastrinomas were significantly smaller than pancreatic gastrinomas (6 vs $24 \mathrm{~mm}, P \leq 0.05$ ). Twenty-four $(86 \%)$ patients had histologically verified malignant tumors as characterized by infiltrating growth and/or the presence of lymph node or distant metastases.

Table 1 Results of pancreatic-duodenal homeobox 1 (Pdx1), Shh and PP immunohistochemistry in 28 patients with gastrinomas

\begin{tabular}{|c|c|c|c|c|c|c|c|c|c|c|}
\hline No. & $\begin{array}{c}\text { Age } \\
\text { (years) }\end{array}$ & Gender & MEN1 & $\begin{array}{l}\text { Site of } \\
\text { gastrinoma }\end{array}$ & $\begin{array}{l}\text { Tumor } \\
\text { size }(\mathrm{mm})\end{array}$ & $\begin{array}{l}\text { Tissue } \\
\text { analyzed }\end{array}$ & $\begin{array}{l}\text { Pdx1 } \\
\text { IHC }\end{array}$ & $\begin{array}{l}\text { Shh } \\
\text { IHC }\end{array}$ & $\begin{array}{l}\text { PP } \\
\text { IHC }\end{array}$ & $\begin{array}{l}\text { Follow-up } \\
\text { (months) }\end{array}$ \\
\hline 1 & 57 & $M$ & No & Pancreas & 33 & Primary tumor & ++ & - & + & 97/AWD \\
\hline 2 & 28 & $\mathrm{~F}$ & No & Duodenum & 3 & Primary tumor & - & ++ & - & 112/NED \\
\hline 3 & 44 & $\mathrm{~F}$ & No & Pancreas & - & Liver-met. & + & - & - & 132 NED \\
\hline 4 & 54 & $M$ & No & Duodenum & 10 & Primary tumor & - & ++ & - & 165/AWD \\
\hline 5 & 49 & $\mathrm{~F}$ & No & Duodenum & 15 & Primary tumor & - & ++ & - & 101/NED \\
\hline 6 & 33 & $\mathrm{~F}$ & No & Duodenum & 8 & Primary tumor & - & ++ & - & 236/AWD \\
\hline 7 & 61 & M & No & Unknown & - & LN-metastasis & - & ++ & - & 47/AWD \\
\hline \multirow[t]{2}{*}{8} & 59 & M & No & Pancreas & 43 & Primary tumor & + & - & + & 57/DOD \\
\hline & & & & & - & LN-metastasis & + & - & - & \\
\hline 9 & 36 & $F$ & No & Unknown & - & LN-metastasis & - & + & - & 71/AWD \\
\hline 10 & 64 & $\mathrm{~F}$ & No & Pancreas & 40 & Primary tumor & ++ & - & - & 3/DOD \\
\hline 11 & 73 & $\mathrm{~F}$ & No & Pancreas & 20 & Primary tumor & + & - & - & 88/NED \\
\hline 12 & 59 & $\mathrm{M}$ & No & Pancreas & 10 & Primary tumor & ++ & - & + & 15/DURC \\
\hline 13 & 70 & $\mathrm{~F}$ & No & Duodenum & 4 & Primary tumor & - & ++ & - & 153/NED \\
\hline 14 & 43 & M & No & Pancreas & - & Liver-met. & ++ & - & - & 180/AWD \\
\hline 15 & 58 & $\mathrm{~F}$ & No & Pancreas & - & Liver-met. & + & - & + & 1/DOD \\
\hline \multirow[t]{2}{*}{16} & 52 & $\mathrm{~F}$ & No & Duodenum & 5 & Primary tumor & - & ++ & - & 58/NED \\
\hline & & & & & - & LN-metastasis & - & ++ & - & \\
\hline \multirow[t]{2}{*}{17} & 46 & $\mathrm{~F}$ & No & Duodenum & 5 & Primary tumor & - & ++ & - & 15/AWD \\
\hline & & & & & - & LN-metastasis & - & ++ & - & \\
\hline \multirow[t]{2}{*}{18} & 50 & $\mathrm{~F}$ & No & Duodenum & 8 & Primary tumor & - & ++ & - & 15/AWD \\
\hline & & & & & - & LN-metastasis & - & ++ & - & \\
\hline 19 & 59 & $\mathrm{~F}$ & No & Pancreas & 22 & Primary tumor & ++ & - & + & 5/NED \\
\hline 20 & 48 & M & Yes & Duodenum & 10 & Primary tumor & - & ++ & - & 152/AWD \\
\hline 21 & 49 & M & Yes & Duodenum & 3 & Primary tumor & - & ++ & - & 117/AWD \\
\hline 22 & 29 & $M$ & Yes & Duodenum & 8 & Primary tumor & - & ++ & - & 54/AWD \\
\hline 23 & 46 & $\mathrm{~F}$ & Yes & Duodenum & 3 & Primary tumor & - & ++ & - & 126/AWD \\
\hline 24 & 48 & M & Yes & Duodenum & 6 & Primary tumor & - & ++ & - & 56/AWD \\
\hline 25 & 47 & M & Yes & Duodenum & 3 & Primary tumor & - & ++ & - & 118/AWD \\
\hline \multirow[t]{2}{*}{26} & 45 & $\mathrm{~F}$ & Yes & Pancreas & 25 & Primary tumor & ++ & - & + & 93/AWD \\
\hline & & & & & - & LN-metastasis & ++ & - & + & \\
\hline 27 & 32 & $\mathrm{~F}$ & Yes & Pancreas & 12 & Primary tumor & + & - & + & 160/AWD \\
\hline 28 & 50 & M & Yes & Duodenum & 6 & Primary tumor & - & + & - & 21/AWD \\
\hline
\end{tabular}

MEN1, multiple endocrine neoplasia type 1; LN-metastasis, lymph node metastasis; Liver-met., liver metastasis; DOD, dead of disease; AWD, alive with disease; NED, no evidence for disease; DURC, death of unrelated cause; IHC, immunohistochemistry; Shh, sonic hedgehog; PP, pancreatic polypeptide. 


\section{Pdx1 is expressed in pancreatic gastrinomas and their associated metastases}

Immunohistochemical staining revealed expression of Pdx 1 in all pancreatic gastrinomas tested (Table 1 and Fig. 1C). Pdx 1 positive tumors cells showed a typical nuclear staining pattern as seen in normal islet cells and were found to be distributed throughout large areas of the tumors. Pdx 1 was also expressed in all associated lymph node $(n=2)$ or liver metastases $(n=3)$ from pancreatic gastrinomas analyzed (Table 1).

\section{Shh is not expressed in pancreatic gastrinomas and their associated metastases}

In all pancreatic gastrinomas analyzed, expression of Shh was not detected (Table 1 and Fig. 1D). Furthermore, all the associated metastases did not show any expression of Shh.
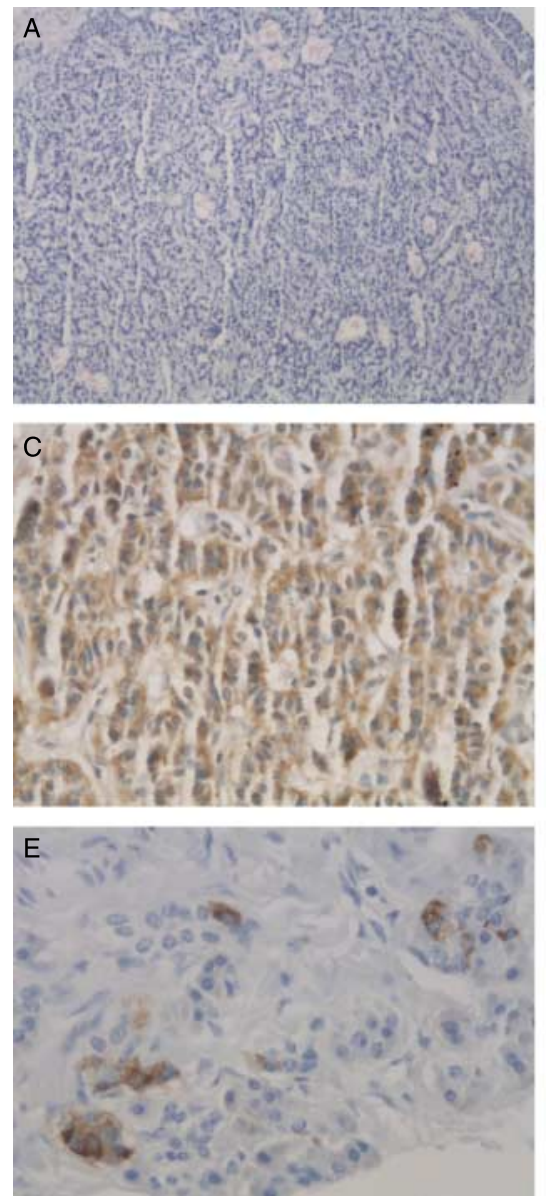

\section{PP is expressed in some pancreatic gastrinomas}

PP expression was found in 7 out of 11 pancreatic gastrinomas (Table 1 and Fig. 1E). Furthermore, we found a diffuse PP hyperplasia in a ZES-MEN1 patient with a pancreatic gastrinoma (Fig. 4A and B).

\section{Pdx1 is not expressed in duodenal gastrinomas and their associated metastases}

In all duodenal gastrinomas analyzed, $\mathrm{Pdx} 1$ expression was absent (Table 1 and Fig. 2C). Pdx1 was also undetectable in all associated lymph node metastases $(n=3)$ from duodenal gastrinomas analyzed (Table 1, data not shown).

\section{Shh is expressed in duodenal gastrinomas and their associated metastases}

In contrast to pancreatic gastrinomas, Shh was expressed in all duodenal gastrinomas (Table 1 and
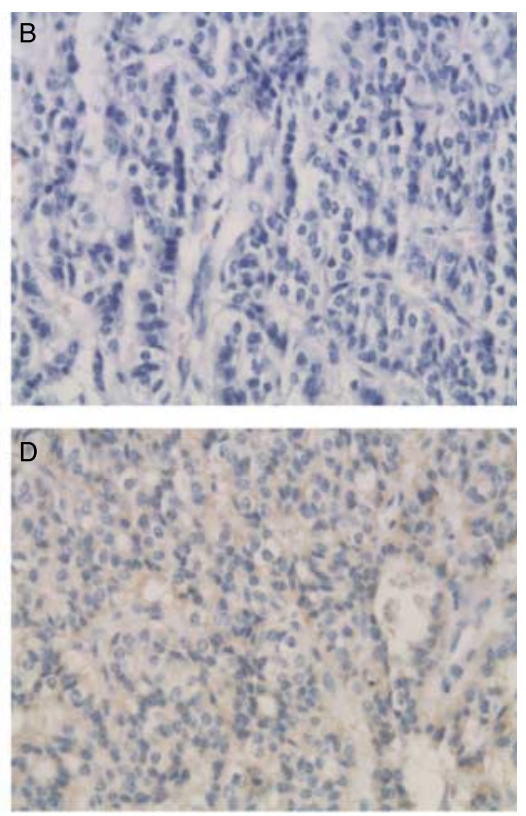

Figure $1 \mathrm{IHC}$ staining of pancreatic gastrinoma. (A) H\&E staining (10×). (B) H\&E staining (40×). (C) Representative example of $\mathrm{Pdx} 1$ expression in a pancreatic gastrinoma, showing a typical nuclear staining pattern for the transcription factor. (D) Absence of Sonic hedgehog staining in the same tumor. (E) Positive staining for pancreatic polypeptide in some pancreatic gastrinoma cells. Full colour version of this figure available via http://dx.doi.org/10.1677/ERC-08-0204. 

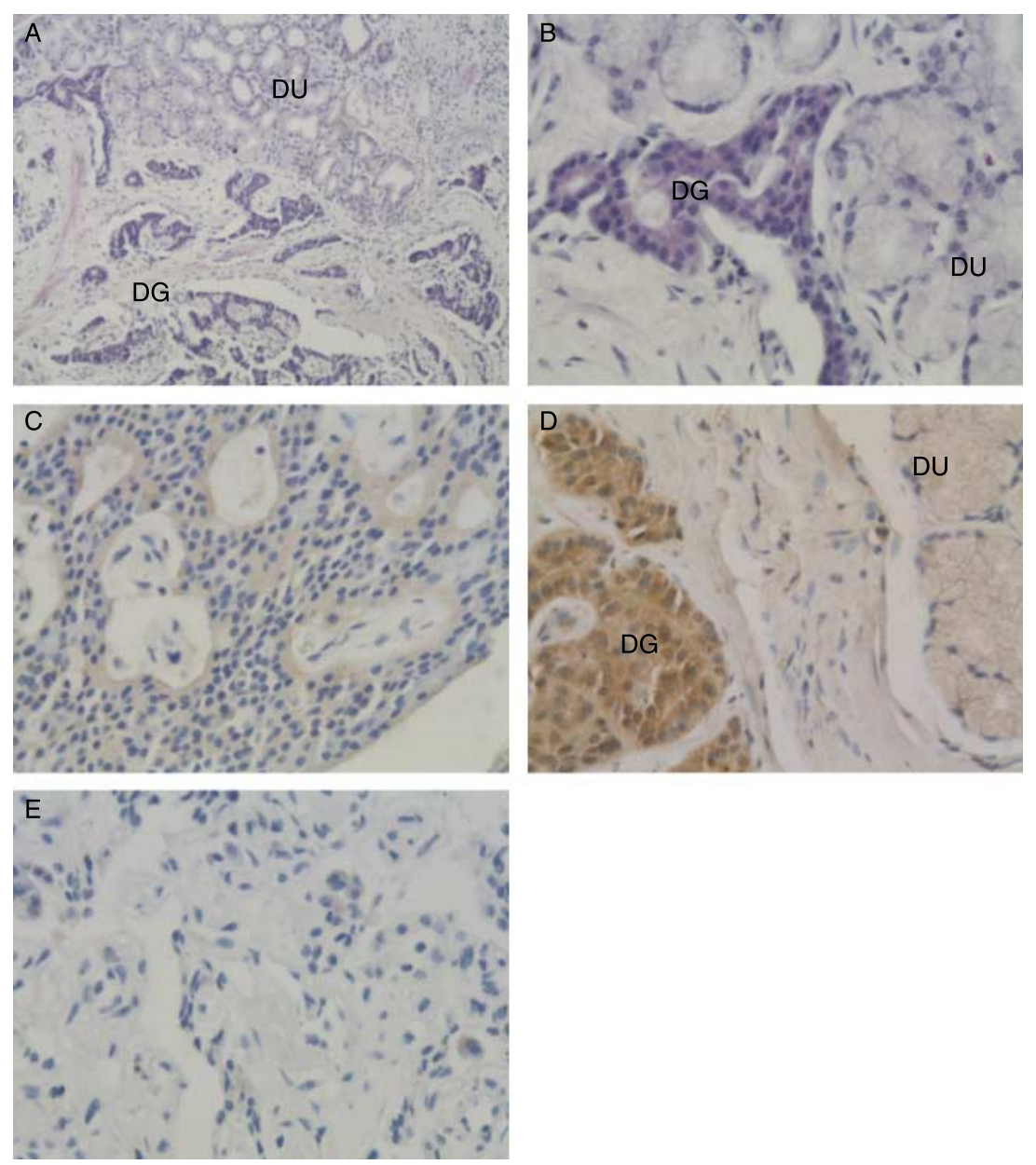

Figure 2 IHC staining of duodenal gastrinoma. (A) H\&E staining showing a dudoenal gastrinoma (DG) in the typical sumucosal layer in the duodenum (DU; $10 \times)$. (B) H\&E staining $(40 \times)$. (C) Lack of Pdx1 expression in duodenal gastrinoma. (D) Marked overexpression of Sonic hedgehog in DG and weak expression in adjacent normal DU. (E). Lack of staining for pancreatic polypeptide. Full colour version of this figure available via http://dx.doi.org/10.1677/ERC-08-0204.

Fig. 2D). Tumor cells expressing SHH were found to be distributed throughout large areas of the tumors. Shh was also detectable in all associated lymph node metastases $(n=3)$. As expected, SHH expression was also seen in normal intestinal epithelium (Fig. 2D).

\section{PP is not expressed in duodenal gastrinomas}

Expression of PP was not seen in any duodenal gastrinoma examined (Table 1 and Fig. 3E).

\section{Expression of Pdx1, Shh, and PP in metastases from gastrinomas with unknown origin}

Pdx1 expression was absent in both lymph node metastases from the two patients with an unknown location of the primary (Table 1 and Fig. 3B).
Furthermore, we found expression of Shh in both cases suggesting a so far undetected duodenal gastrinoma (Table 1 and Fig. 3C). PP was not expressed on both metastases (Fig. 3D).

\section{Discussion}

After proving the existence of gastrin expression in adult pancreatic tissue, it became clear that pancreatic gastrinomas do not develop by ectopic dedifferentiation of transcription mechanisms, but rather by acceleration of already existing translational and post-translational processing mechanisms (Bardram et al. 1990). Sporadic duodenal gastrinomas usually arise from the first part of the duodenum and are located in the submucosa (Guz et al. 1995). Although studies have shown that both 

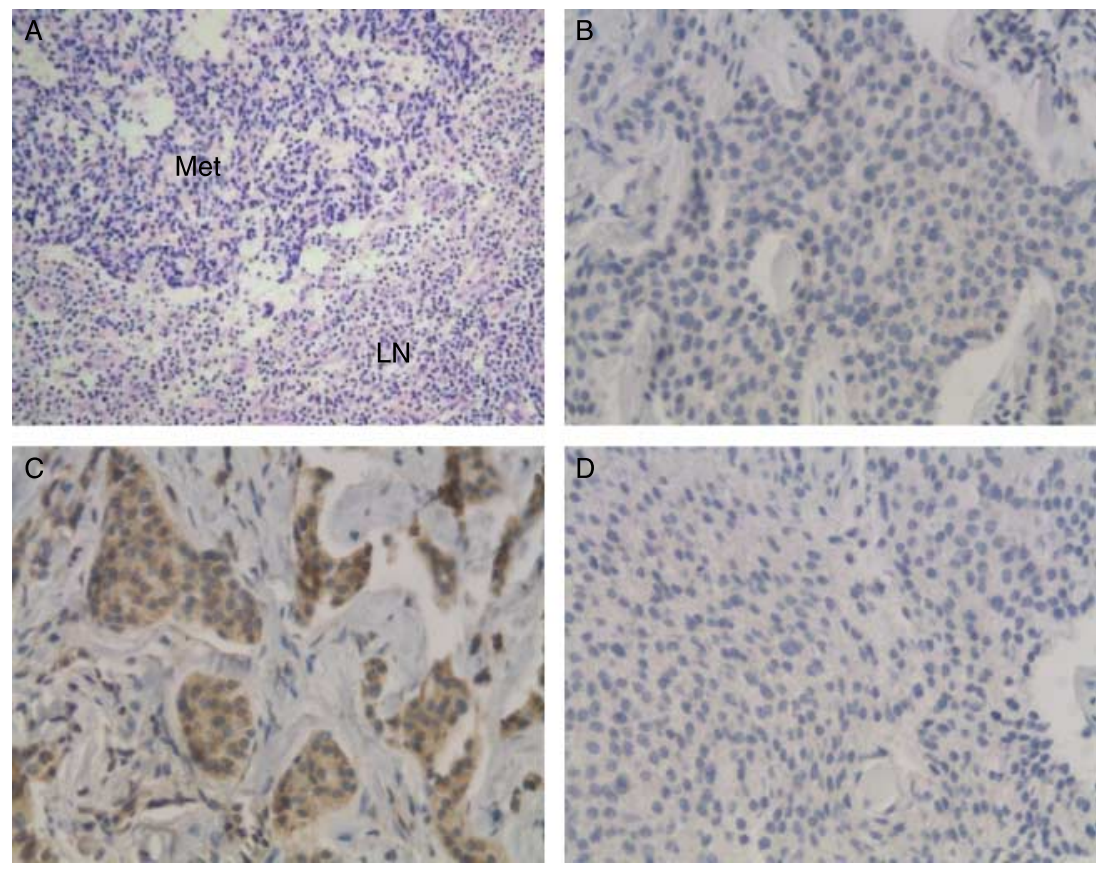

Figure $3 \mathrm{IHC}$ staining of lymph node metastases from patients with so far undetected primary gastrinomas. (A) H\&E staining showing the tumor cells (Met) surrounded by the lymph node (LN). (B) Note the absence of Pdx1 in all the tumor cells, as seen in primary duodenal gastrinomas in Fig. 2. (C) Marked overexpression of SHH suggest a duodenal gastrinoma as primary origin.

(D) Lack of staining for pancreatic polypeptide. Full colour version of this figure available via http://dx.doi.org/10.1677/ERC-08-0204.

locations are equally malignant (40-70\% metastases), and the post-operative disease-free rate is similar (Weber et al. 1995, Norton et al. 1999), the biological behavior of pancreatic and duodenal gastrinomas is quite different. Pancreatic gastrinomas usually have a diameter of $2 \mathrm{~cm}$ or more. Metastasis of pancreatic gastrinomas to regional lymph nodes is found in $\sim 60 \%$ of patients at the time of diagnosis and liver metastases occur more frequently (10-20\%) than in duodenal gastrinomas (Stabile \& Passaro 1985, Norton et al. 2006). Thus, the 10-year survival rate is worse in patients with pancreatic gastrinomas $(57 \%)$ than in patients with duodenal gastrinomas (84\%; Weber et al. 1995, Yu et al. 1999, Norton \& Jensen 2004). Despite the fact that most of the duodenal gastrinomas are smaller than $1 \mathrm{~cm}$, metastases to regional lymph nodes are already found in $60-80 \%$ of the patients at the time of diagnosis. It seems that periduodenal lymph node metastases may grow faster than their duodenal primary tumors and thus may form large tumors that are easily recognized, in contrast to the duodenal primary tumors (Anlauf et al. 2006). Unfortunately, the molecular pathogenesis of gastrinomas contributing to these differences is largely unknown (Fendrich et al. 2007). Molecular data on gastrinoma have been accumulating in recent years, but the genetic basis of endocrine tumor development and progression is still poorly understood (Chen et al. 2003, 2004, Furukawa et al. 2005).

Our study is the first to show that Pdx1 is expressed only in pancreatic, but not in duodenal gastrinomas (Figs 1C and 2C).

The $P d x l$ gene was first described by Miller et al. (1994) and codes for one of the earliest transcriptional factors detected within the developing pancreatic epithelium (Offield et al. 1996). At E9.5, Pdx1 positive cells are seen in the ventral pancreatic primordia and at E11.5, groups of cells adjacent to the pancreatic duct also immunostain for $\mathrm{Pdx} 1$. At E17.5, Pdx1 positive cells in the pancreas were seen exclusively within islets (Peshavaria et al. 1994). In adult tissue, Pdx1 is mainly found in PP and insulin-expressing $\beta$-cells (Leonard et al. 1993, Miller et al. 1994).

In the duodenum of older embryos and adults, almost all cells forming the simple columnar epithelium that line the villi were $\operatorname{Pdx} 1$ positive, whereas the crypt cells did not contain the homeoprotein. Cells of the other layers of the mucosa as well as cells of the submucosa, muscularis and adventitial layers of the wall of the duodenum also lacked Pdx1 expression (Miller et al. 1994, Guz et al. 1995).

The observations of our study suggest that Pdx1 expression might distinguish between duodenal and pancreatic gastrinomas. Driven by these results, we 
searched for another possibility to differentiate these two tumors by IHC. The next marker we analyzed was Shh. The fundamental roles of Hh signaling proteins in embryonic patterning have been established in multicellular organisms ranging from insects to man. The $H h$ gene initially was identified as required for segmental patterning in the Drosophila embryo (Nusslein-Volhard \& Wieschaus 1980), and three mammalian orthologs - Sonic, Indian, and Desert hedgehog - have been subsequently identified that establish morphologic gradients essential for axial patterning of the mammalian embryo. Interestingly, during gastrointestinal development, Shh expression is found within the duodenal tissue that connects the opposing dorsal and ventral buds of the pancreas, resulting in a sharp molecular boundary that separates the duodenal/stomach epithelium from pancreatic tissue (Apelqvist et al. 1997, Hebrok et al. 2000). This pattern, expression in stomach and duodenum and exclusion in pancreatic tissue, is maintained throughout organogenesis (Hebrok et al. 2000, Ramalho-Santos et al. 2000). Now, we found that this expression pattern remains true for pancreatic and duodenal gastrinomas. Whereas Shh expression was absent in all pancreatic gastrinomas, all duodenal gastrinomas showed a strong expression for Shh (Figs 1D and 2D).

In addition, we stained all gastrinomas and metastases for PP. As reported by others (Larsson et al. 1976, Strodel et al. 1984), PP is expressed in pancreatic endocrine tumors. In line with these results, we found expression of PP in a part of pancreatic gastrinomas (Fig. 1E). Interestingly, we found a diffuse PP hyperplasia in a MEN1 patient as described in the literature (Fig. 4). By contrast, we did not find any PP expression in duodenal gastrinomas.

Two patients from our study population have so far undetected primary gastrinomas. Both underwent an abdominal exploration because of proven ZES, and in both cases lymph node metastases had been resected. Even experienced surgeons are sometimes not able to identify a primary tumor in ZES patients although they had lymph nodes containing gastrinoma tissue (Anlauf et al. 2005, 2006, Fendrich et al. 2007). Because in some of these patients, symptomatic and/or biochemical cure seemed to occur after resection of lymph nodes involved by gastrinoma, the existence of primary lymph node gastrinomas was suggested (Norton et al. 2003). This view, however, was challenged when it was demonstrated that duodenal gastrinomas were commonly very small and easily overlooked. Furthermore, we and others have shown that even small duodenal gastrinomas could give rise
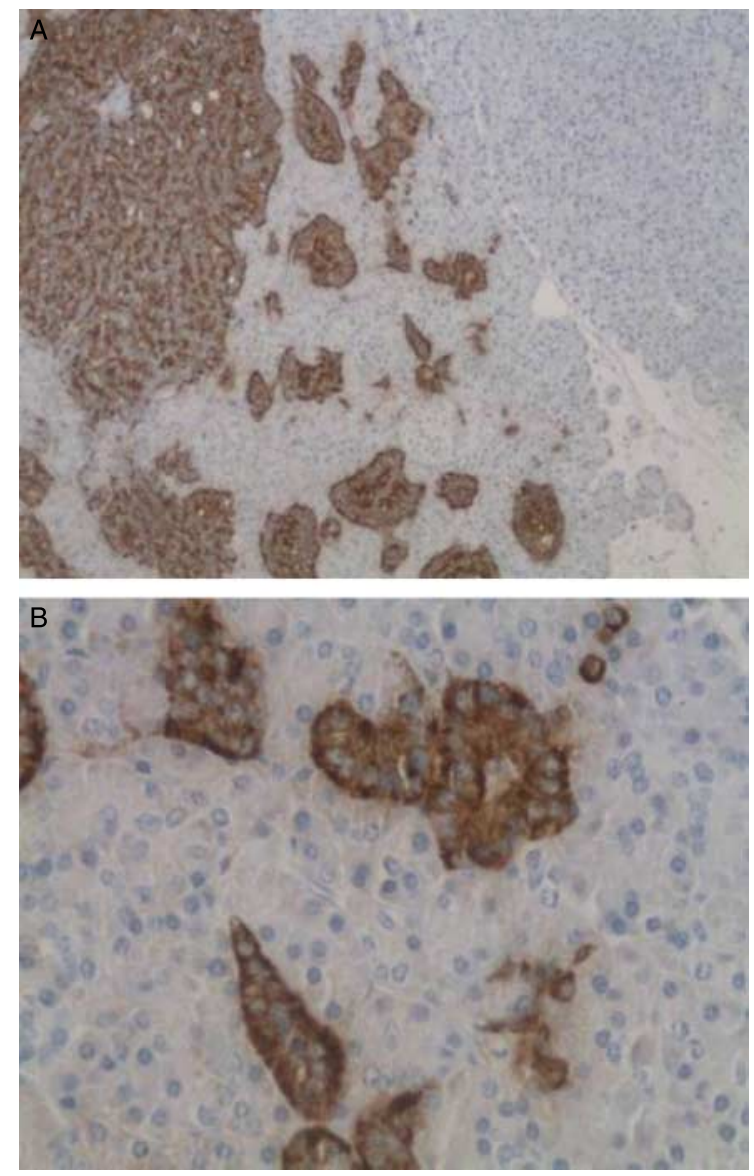

Figure $4 \mathrm{IHC}$ staining for pancreatic polypeptide from a MEN1 patient with a pancreatic gastrinoma. $(A$ and $B)$ Diffuse pancreatic polypeptide hyperplasia. Full colour version of this figure available via http://dx.doi.org/10.1677/ERC-08-0204.

to extensive lymph node metastases (PipeleersMarichal et al. 1990, Akerstrom et al. 2002, Bartsch et al. 2005). In the lymph node metastases investigated in this study by IHC, Pdx1 was not expressed (Fig. 3B). By contrast, both metastases revealed a strong expression of Shh (Fig. 3C), suggesting a so far undetected duodenal gastrinoma.

In conclusion, we show for the first time that only pancreatic, but not duodenal gastrinomas express Pdx1. Moreover, only duodenal gastrinomas express Shh, suggesting a different genetic background of these two tumors. Whereas the expression of Pdx1 in pancreatic gastrinomas might suggest their endocrine origin from islets, duodenal gastrinomas develop from a Pdx1 negative cell cluster. This might be the reason for their different biological behavior. Furthermore, the expression pattern of Pdx1, Shh, and PP in resected metastases can help to locate an otherwise undetected primary gastrinoma. 


\section{Declaration of interest}

The authors declare that there is no conflict of interest that would prejudice the impartiality of this scientific work.

\section{Funding}

V F was supported by a Research Grant from the University Medical Center Giessen and Marburg.

\section{References}

Akerstrom G, Hessman O \& Skogseid B 2002 Timing and extent of surgery in symptomatic and asymptomatic neuroendocrine tumors of the pancreas in MEN1. Langenbeck's Archives of Surgery 386 558-569.

Anlauf M, Perren A, Meyer CL, Schmid S, Saremaslani P, Kruse ML, Weihe E, Komminoth P, Heitz PU \& Klöppel G 2005 Precursor lesions in patients with multiple endocrine neoplasia type 1-associated duodenal gastrinomas. Gastroenterology 128 1187-1198.

Anlauf M, Garbrecht N, Henopp T, Schmitt A, Schlenger R, Raffel A, Krausch M, Gimm O, Eisenberger CF, Knoefel WT et al. 2006 Sporadic versus hereditary gastrinomas of the duodenum and pancreas: distinct clinico-pathological and epidemiological features. World Journal of Gastroenterology 12 5440-5446.

Apelqvist A, Ahlgren U \& Edlund H 1997 Sonic hedgehog directs specialised mesoderm differentiation in the intestine and pancreas. Current Biology 7 801-804.

Bardram L, Hilsted L \& Rehfeld JF 1990 Progastrin expression in mammalian pancreas. PNAS 87 298-302.

Bartsch DK, Fendrich V, Langer P, Celik I, Kann PH \& Rothmund M 2005 Outcome of duodenopancreatic resections in patients with multiple endocrine neoplasia type 1. Annals of Surgery 242 757-764.

Brand SJ \& Fuller PJ 1988 Differential gastrin gene expression in rat gastrointestinal tract and pancreas during neonatal development. Journal of Biological Chemistry 263 5341-5347.

Cano DA, Hebrok M \& Zenker M 2007 Pancreatic development and disease. Gastroenterology 132 745-762.

Chen YJ, Vortmeyer A, Zhuang Z, Huang S \& Jensen RT 2003 Loss of heterozygosity of chromosome 1q in gastrinomas: occurrence and prognostic significance. Cancer Research 63 817-823.

Chen YJ, Vortmeyer A, Zhuang Z, Gibril F \& Jensen RT 2004 X-chromosome loss of heterozygosity frequently occurs in gastrinomas and is correlated with aggressive tumor growth. Cancer 100 1379-1387.

Donow C, Pipeleers-Marichal M, Schröder S, Stamm B, Heitz PU \& Klöppel G 1991 Surgical pathology of gastrinoma. Site, size, multicentricity, association with multiple endocrine neoplasia type 1 , and malignancy. Cancer 68 1329-1334.
Esni F, Stoffers DA, Takeuchi T \& Leach SD 2004 Origin of exocrine pancreatic cells from nestin-positive precursors in developing mouse pancreas. Mechanisms of Development 121 15-25.

Fendrich V, Langer P, Celik I, Bartsch DK, Zielke A, Ramaswamy A \& Rothmund M 2006 An aggressive surgical approach leads to long-term survival in patients with pancreatic endocrine tumors. Annals of Surgery 244 845-853.

Fendrich V, Langer P, Waldmann J, Bartsch DK \& Rothmund M 2007 Management of sporadic and multiple endocrine neoplasia type 1 gastrinomas. British Journal of Surgery 94 1331-1341.

Fendrich V, Esni F, Garay MV, Feldmann G, Habbe N, Jensen JN, Dor Y, Stoffers D, Jensen J, Leach SD et al. 2008 Hedgehog signalling regulates facultative progenitor activity in regenerating exocrine pancreas. Gastroenterology 135 621-631.

Furukawa M, Raffeld M, Mateo C, Sakamoto A, Moody TW, Ito T, Venzon DJ, Serrano J \& Jensen RT 2005 Increased expression of insulin-like growth factor I and/or its receptor in gastrinomas is associated with low curability, increased growth, and development of metastases. Clinical Cancer Research 11 3233-3242.

Guz Y, Montminy MR, Stein R, Leonard J, Gamer LW, Wright CVE \& Teitelman G 1995 Expression of murine STF-1, a putative insulin gene transcription factor, in $\beta$ cells of pancreas, duodenal epithelium and pancreatic exocrine and endocrine progenitors during ontogeny. Development 121 149-161.

Hebrok M, Kim SK, St Jacques B, McMahon AP \& Melton DA 2000 Regulation of pancreas development by hedgehog signaling. Development 127 4905-4913.

Hoffmann KM, Furukawa M \& Jensen RT 2005 Duodenal neuroendocrine tumors: classification, functional syndromes, diagnosis and medical treatment. Best Practice \& Research. Clinical Gastroenterology 19 675-697.

Imamura M, Takahashi K, Adachi H, Minematsu S, Shimada Y, Naito M, Suzuki T, Tobe T \& Azuma T 1987 Usefulness of selective arterial secretin injection test for localization of gastrinoma in the Zollinger-Ellison syndrome. Annals of Surgery 205 230-239.

Imamura M, Kanda M, Takahashi K, Shimada Y, Miyahara T, Wagata T, Hashimoto M, Tobe T \& Soga J 1992 Clinicopathological characteristics of duodenal microgastrinomas. World Journal of Surgery 16 703-709.

Jensen JN, Cameron E, Garay MV, Starkey TW, Gianani R \& Jensen J 2005 Recapitulation of elements of embryonic development in adult mouse pancreatic regeneration. Gastroenterology 128 728-741.

Kimmel JR, Pollock HG \& Hazelwood RL 1968 Isolation and characterization of chicken insulin. Endocrinology $\mathbf{8 3}$ 1323-1330. 
Klöppel G, Rindi G, Anlauf M, Perren A \& Komminoth P 2007 Site-specific biology and pathology of gastroenteropancreatic neuroendocrine tumors. Virchows Archiv 451 S9-S27.

Larsson LI, Schwartz T, Lundqvist G, Chance RE, Sundler F, Rehfeld JF, Grimelius L, Fahrenkrug J, Schaffalitzky de Muckadell O \& Moon N 1976 Occurrence of human pancreatic polypeptide in pancreatic endocrine tumors. Possible implication in the watery diarrhea syndrome. American Journal of Pathology 85 675-684.

Leonard J, Peers B, Johnson T, Ferreri K, Lee S \& Montminy MR 1993 Characterization of somatostatin transactivating factor-1, a novel homeobox factor that stimulates somatostatin expression in pancreatic islet cells. Molecular Endocrinology 7 1275-1283.

Liu T, Gou SM, Wang CY, Wu HS, Xiong JX \& Zhou F 2007 Pancreas duodenal homeobox-1 expression and significance in pancreatic cancer. World Journal of Gastroenterology 13 2615-2618.

Miller CP, McGhee RE \& Habener JF 1994 IDX-1: a new homeodomain transcription factor expressed in rat pancreatic islets and duodenum that transactivates the somatostatin gene. EMBO Journal 13 1145-1156.

Norton JA \& Jensen RT 2004 Resolved and unresolved controversies in the surgical management of patients with Zollinger-Ellison syndrome. Annals of Surgery $\mathbf{2 4 0}$ 757-773.

Norton JA, Fraker DL, Alexander HR, Venzon DJ, Doppman JL, Serrano J, Goebel SU, Peghini PL, Roy PK, Gibril F et al. 1999 Surgery to cure the Zollinger-Ellison syndrome. New England Journal of Medicine 341 635-644.

Norton JA, Alexander HR, Fraker DL, Venzon DJ, Gibril F \& Jensen RT 2003 Possible primary lymph node gastrinoma: occurrence, natural history, and predictive factors: a prospective study. Annals of Surgery 237 650-657.

Norton JA, Fraker DL, Alexander HR, Gibril F, Liewehr DJ, Venzon DJ \& Jensen RT 2006 Surgery increases survival in patients with gastrinoma. Annals of Surgery 244 410-419.

Nusslein-Volhard C \& Wieschaus E 1980 Mutations affecting segment number and polarity in Drosophila. Nature 287 795-801.

Offield MF, Jetton TL, Labosky PA, Ray M, Stein R, Magnuson MA, Hogan BLM \& Wright CVE 1996 PDX-1 is required for pancreatic outgrowth and differentiation of the rostral duodenum. Development 122 983-995.

Peshavaria M, Gamer L, Henderson E, Teitelman G, Wright CVE \& Stein R 1994 XIHbox 8, an endodermspecific Xenopus homeodomain protein, is closely related to a mammalian insulin gene transcription factor. Molecular Endocrinology 8 806-816.

Pipeleers-Marichal M, Somers G, Willems G, Foulis A, Imrie C, Bishop AE, Polak JM, Häcki WH, Stamm B, Heitz PU et al. 1990 Gastrinomas in the duodenums of patients with multiple endocrine neoplasia type 1 and the Zollinger-Ellison syndrome. New England Journal of Medicine 322 723-727.

Ramalho-Santos M, Melton DA \& McMahon AP 2000 Hedgehog signals regulate multiple aspects of gastrointestinal development. Development 127 2763-2772.

Song SY, Gannon M, Washington MK, Scoggins CR, Meszoely IM, Goldenring JR, Marino CR, Sandgren EP, Coffey RJ Jr, Wright CV et al. 1999 Expansion of Pdx1-expressing pancreatic epithelium and islet neogenesis in transgenic mice overexpressing transforming growth factor alpha. Gastroenterology 117 1416-1426.

Stabile BE \& Passaro E Jr 1985 Benign and malignant gastrinoma. American Journal of Surgery 149 144-150.

Stabile BE, Morrow DJ \& Passaro E 1987 The gastrinoma triangle: operative implications. American Journal of Surgery 209550.

Stoffers DA, Heller RS, Miller CP \& Habener JF 1999 Developmental expression of the homeodomain protein IDX-1 in mice transgenic for an IDX-1 promoter/lacZ transcriptional reporter. Endocrinology 140 5374-5381.

Strodel WE, Vinik AI, Lloyd RV, Glaser B, Eckhauser FE, Fiddian-Green RG, Turcotte JG \& Thompson NW 1984 Pancreatic polypeptide-producing tumors. Silent lesions of the pancreas? Archives of Surgery 119 508-514.

Sugg SL, Norton JA, Fraker DL, Metz DC, Pisegna JR, Fishbeyn V, Benya RV, Shawker TH, Doppman JL \& Jensen RT 1993 A prospective study of intraoperative methods to find and resect duodenal gastrinomas. Annals of Surgery 218 138-144.

Thompson NW 1998 Management of pancreatic endocrine tumors in patients with multiple endocrine neoplasia type 1. Surgical Clinics of North America 7 881-891.

Weber HC, Venzon DJ, Fishbein VA, Lin JT, Orbuch M, Strader DB, Gibril F, Metz DC, Fraker DL, Norton JA et al. 1995 Determinants of metastatic rate and survival in patients with Zollinger-Ellison syndrome: a prospective long-term study. Gastroenterology 108 1637-1649.

Yu F, Venzon DJ, Serrano J, Goebel SU, Doppman JL, Gibril F \& Jensen RT 1999 Prospective study of the clinical course, prognostic factors, causes of death, and survival in patients with long-standing Zollinger-Ellison syndrome. Journal of Clinical Oncology 17 615-630.

Zogakis TG, Gibril F, Libutti SK, Norton JA, White DE, Jensen RT \& Alexander HR 2003 Management and outcome of patients with sporadic gastrinoma arising in the duodenum. Annals of Surgery 238 42-48.

Zollinger RM \& Ellison EH 1955 Primary peptic ulcerations of the jejunum associated with islet cell tumors of the pancreas. Annals of Surgery 142 709-723. 